\title{
Desenvolvimento de cultivares de soja de crescimento indeterminado após a poda
}

\section{apical}

\author{
Development of indetermined growth soy cultivars after apical pruning \\ Desarrollo de cultivares de soja de crecimiento indeterminado tras la poda apical
}

Recebido: 09/03/2021 | Revisado: 16/03/2021 | Aceito: 29/04/2021 | Publicado: 13/05/2021

\author{
Gustavo Henrique de Oliveira Dias \\ ORCID: https://orcid.org/0000-0001-7291-6569 \\ Fundação Educacional de Andradina, Brasil \\ E-mail: gustavohd09@gmail.com \\ Lucas Aparecido Manzani Lisboa \\ ORCID: https://orcid.org/0000-0001-9013-232X \\ Fundação Educacional de Andradina, Brasil \\ E-mail: lucas@fea.br \\ João Paulo Dal Santo Ferreira \\ ORCID: https://orcid.org/0000-0001-8540-137X \\ Fundação Educacional de Andradina, Brasil \\ E-mail: jotapeferreira20@gmail.com \\ Edison Alves Rocha \\ ORCID: https://orcid.org/0000-0003-3559-9343 \\ Universidade Estadual Paulista, Brasil \\ E-mail: edison.rocha@unesp.br
}

\begin{abstract}
Resumo
Algumas cultivares de soja de ciclo perene podem apresentar plasticidade na brotação dos ramos laterais, ou mesmo, pode ser estimulado após a sua poda apical em diferentes estádios fenológicos da cultura. Diante do exposto esse trabalho teve por objetivo avaliar o desenvolvimento de cultivares de soja de crescimento indeterminado após a poda apical. O experimento foi realizado em outubro de 2019, nas Faculdades Integradas Stella Maris (FISMA), localizada no Município de Andradina, Estado de São Paulo. O delineamento foi inteiramente casualizado, em esquema fatorial de 2x4, sendo dois cultivares de soja, DM81I84 IPRO e SYN 1687 IPRO, interagindo com a poda apical em quatro estádios diferentes de desenvolvimento, sendo eles: ausência de poda (controle), V4, V8 e R2, perfazendo oito tratamentos e com cinco repetições, totalizando 40 parcelas ou vasos. Não é recomendada a poda apical nas cultivares de soja DM81I84 IPRO e SYN 1687 IPRO. A poda apical na fase reprodutiva da soja influência de maneira negativa a produtividade da cultura. A cultivar de soja DM81I84 IPRO se destacou nas características de produção. O número de galhos apresenta uma correlação positiva com a produtividade na cultura da soja.
\end{abstract}

Palavras-chave: Glycine max; Estádio fenológico; Galhos; Vagem.

\begin{abstract}
Some soybean cultivars of perennial cycle may show plasticity in the sprouting of the lateral branches, or even, it can be stimulated after their apical pruning in different phenological stages of the culture. Given the above, this work aimed to evaluate the development of soybean cultivars of indeterminate growth after apical pruning. The experiment was carried out in October 2019, at Faculdades Integradas Stella Maris (FISMA), located in the city of Andradina, State of São Paulo. The design was completely randomized, in a 2x4 factorial scheme, with two soybean cultivars, DM81I84 IPRO and SYN 1687 IPRO, interacting with apical pruning in four different stages of development, namely: pruning (control), V4, V8 and R2, making eight treatments and with five repetitions, totaling 40 plots or vessels. Apical pruning on soybean cultivars DM81I84 IPRO and SYN 1687 IPRO is not recommended. Apical pruning in the soybean reproductive phase has a negative influence on crop productivity. A soybean cultivar DM81I84 IPRO stood out in the production characteristics. The number of branches has a positive correlation with productivity in soybean.
\end{abstract}

Keywords: Glycine max; Phenological stage; Branches; Pod.

\section{Resumen}

Algunos cultivares de soja de ciclo perenne pueden presentar plasticidad en la brotación de las ramas laterales, o incluso, puede ser estimulada luego de su poda apical en diferentes etapas fenológicas del cultivo. Dado lo anterior, este trabajo tuvo como objetivo evaluar el desarrollo de cultivares de soja de crecimiento indeterminado después de la poda apical. El experimento se realizó en octubre de 2019, en las Faculdades Integradas Stella Maris (FISMA), 
ubicada en el Municipio de Andradina, Estado de São Paulo. El diseño fue completamente al azar, en un esquema factorial 2x4, con dos cultivares de soja, DM81I84 IPRO y SYN 1687 IPRO, interactuando con la poda apical en cuatro etapas diferentes de desarrollo, a saber: ausencia de poda (control), V4, V8 y R2, realizando ocho tratamientos y con cinco repeticiones, totalizando 40 parcelas o vasijas. No se recomienda la poda apical para los cultivares de soja DM81I84 IPRO y SYN 1687 IPRO. La poda apical en la fase reproductiva de la soja influye negativamente en la productividad del cultivo. En las características de producción se destacó el cultivar de soja DM81I84 IPRO. El número de ramas tiene una correlación positiva con la productividad en soja.

Palabras clave: Glycine max; Etapa fenológica; Sucursales; Vaina.

\section{Introdução}

A soja (Glycine max (L.) Merr) é a leguminosa mais cultivada Brasil, sendo uma cultura extensiva muito importante para a economia brasileira. Está distribuída em praticamente todas as regiões do pais, sendo os estados do Rio Grande do Sul, Mato Grosso, e Paraná são os principais produtores, onde as cultivares obtiveram algumas adaptações quanto ao seu ambiente de produção, e com o passar dos anos, ocupou uma ampla área do cerrado brasileiro (Borém e Miranda,2013; Sediyama et $a l, 2005)$.

A escolha da variedade deve ser realizada levando em consideração a região de adaptação de cada cultivar, grupo de maturação, cultura obtendo uma semente de boa qualidade, onde possibilita uma uniformidade na população de plantas na lavoura, com plantas com alto desempenho, resulta no controle de plantas daninhas, pois fecham as entre linhas de plantio mais rapidamente. Dessa maneira, é importante conhecer a sua fenologia e arquitetura da parte aérea, pois plantas que possuem maior número de galhos, pode favorecer esse fechamento das entre linhas e pode aumentar a sua produtividade devido ao maior número de ramos produtivos, e dessa forma, alguns cultivares de soja de ciclo perene e podem apresentar plasticidade nas condições de estresse hídrico, pois após esse período podem rebrotar ou mesmo após ataque de pragas (Embrapa, 2013a).

Uma nova estratégia que já está sendo empregada na cultura da soja é a poda do ramo principal a fim de garantir uma maior ramificação. A planta tende a se regenerar a parte aérea a partir das gemas axilares, por meio da quebra da dominância apical (Correia et al, 2005). Dessa forma, é importante conhecer o estádio desenvolvimento ideal que deve ser realizada essa poda, pois dependendo do seu estádio fenológico irá apresentar um comportamento diferente no desenvolvimento desses ramos, que pode afetar o florescimento e consequentemente a qualidade e produção da planta (Wilkie et al, 2008). Essa poda desencadeia uma cascata de reações bioquímicas na planta, principalmente na rota da síntese das auxinas, pois a sua produção passa a ser comprometido, o que leva a perda da dominância apical. Devido a esse fator limitante, ocorre o estímulo da brotação lateral provocado pela a ação da citocinina (Taiz et al, 2017).

$\mathrm{O}$ gradiente de auxina molda a estrutura da planta regulando a sua divisão celular e subsequente o seu desenvolvimento, que possibilita o surgimento de ramos laterais mais robustos e mais espessos, o que pode possibilitar um melhor fechamento das entre linhas de cultivo, o que pode levar uma melhor produtividade (Benková et al, 2003; Yoshihara e Spalding, 2017).

A dominanancia apical é o controle exercido pelas porçoes apicais do caule sobre o crescimento dos ramos laterais, alternativamente a perda de auxina produzida no apice, ocorre o crescimento dos ramos laterias, ocorrendo a inibiçãoe o desenvolvimento da exportação de auxina a partir dessa perda das auxinas ocorre o desenvolvimento dos ramos laterais e o alongamentodo caula da planta (Cline, 1991).

As auxinas são substâncias essenciais no desenvolvimento de plantas, pois promovem modificações na parede celular durante o processo de divisão celular, permitindo a extensibilidade da célula, estimula o alongamento celular e a formação de novos tecidos. Podem também estimular várias respostas fisiológicas quando utilizadas na indução de ramos laterais, folhas, gemas axilares ou apicais, embriões e calos. As auxinas e citocininas atuam diretamente no desenvolvimento 
de tecidos e células meristemáticas, atuando fortemente na divisão celular, diferenciação celular, desenvolvimento de caules e folhas, na quebra da dominância apical, na formação de brotos, (Silva et al, 2020).

Diante do exposto esse trabalho teve por objetivo avaliar o desenvolvimento de cultivares de soja de crescimento indeterminado após a poda apical.

\section{Material e Métodos}

O experimento foi realizado em outubro de 2019, nas Faculdades Integradas Stella Maris (FISMA), localizada no Município de Andradina, Estado de São Paulo, nas coordenadas geográficas $20^{\circ} 53 ' 26,482^{\prime \prime S}$ e $51^{\circ} 22^{\prime 2} 24,822^{\prime \prime}$ W e com altitude de 396 metros acima do nível do mar. O delineamento foi inteiramente casualizado, em esquema fatorial de $2 \times 4$, sendo dois cultivares de soja, DM81I84 IPRO e SYN 1687 IPRO, interagindo com a poda apical em quatro estádios diferentes de desenvolvimento, sendo eles: ausência de poda (controle), V4, V8 e R2 (Fehr e Caviness, 1977 adaptado), perfazendo oito tratamentos com cinco repetições, totalizando 40 parcelas ou vasos.

Os vasos continham a capacidade volumétrica de nove $\mathrm{dm}^{3}$ e foram preenchidos com solo originado da camada de 00,3 m classificado como Latossolo Vermelho hipoférrico (Embrapa, 2013b) e apresentava os seguintes atributos químicos, conforme apresentado na Tabela 1.

Tabela 1: Atributos químicos do solo utilizado no experimento.

\begin{tabular}{|c|c|c|c|c|c|c|c|c|c|c|c|}
\hline $\mathrm{pH}$ & MO & $\mathrm{P}$ & K & $\mathrm{Ca}$ & $\mathrm{Mg}$ & $\mathrm{H}+\mathrm{Al}$ & $\mathrm{Al}$ & SB & CTC & $\mathrm{V} \%$ & $\mathrm{~m} \%$ \\
\hline $\mathrm{CaCl}_{2}$ & $\mathrm{~g} \mathrm{dm}^{-3}$ & $\mathrm{mg} \mathrm{dm}^{-3}$ & & & --- & ----- & $\mathrm{nmc}$ & -3 & --- & & \\
\hline 5,9 & 11 & 21 & 2,0 & 19 & 7,0 & 15 & 0 & 28 & 43 & 65 & 0 \\
\hline
\end{tabular}

SB: Soma de bases; V\%: Saturação por bases; m\%: Saturação por alumínio. Fonte: Autores.

O solo foi adubado conforme as exigências da cultura da soja, segundo Raij et al, (1996), e em seguida, foi semeada a cinco centímetros de profundidade três sementes viáveis. No estádio V4 foi selecionada a melhor planta que passou a compor cada parcela. Durante a condução do experimento, os vasos foram irrigados até atingir a capacidade de campo e todos os tratos culturais foram realizados.

No estádio R6 foram mensurados os seguintes parâmetros: altura de planta (AP) determinada através do uso de uma trena graduada em milímetros; número total de folíolo (NTF) determinado através da contagem direta na planta; diâmetro do caule (DC) determinado abaixo do surgimento da primeira brotação lateral onde e foi utilizado um paquímetro graduado em milímetros; número de galhos (NG) determinado através da contagem direta na planta. Também no estádio R8 (colheita) foi determinado o número de ( $\mathrm{NGr}$ ) através da contagem direta e a produtividade em $\mathrm{kg} \mathrm{ha}^{-1}$, em base úmida de $14 \%$ nos grãos, e foi estimada em uma densidade de 300 mil plantas por hectare.

Todos os parâmetros foram submetidos ao teste $\mathrm{F}(\mathrm{p}<0,05)$ e foi aplicado o Teste de Tukey a $5 \%$ de probabilidade (Banzatto e Kronka, 2013). Também foi realizada uma correlação Pearson, onde foi utilizado o programa estatístico R (R Core Team, 2015).

\section{Resultados e Discussão}

Foi observado na Tabela 2 que não houve uma interação entre os fatores para o parâmetro altura de plantas (AP). Porém, foi observado separadamente um efeito significativo para o fator cultivar onde a SYN 1687 IPRO apresentou maior altura de planta, com aproximadamente 13,51\% a mais em relação à outra cultivar. Também foi observada uma diferença 
significativa para o fator poda em estádios fenológicos da soja, onde a ausência de poda apresentou as maiores médias com aproximadamente $24,39 \%$ em relação ao estádio R2.

Tabela 2: Valores médios de altura de planta (AP), número total de folíolo (NTF), diâmetro do caule da planta (DC) e número de galhos (NG) da soja após a poda apical em diferentes estádios fenológicos. Andradina 2020.

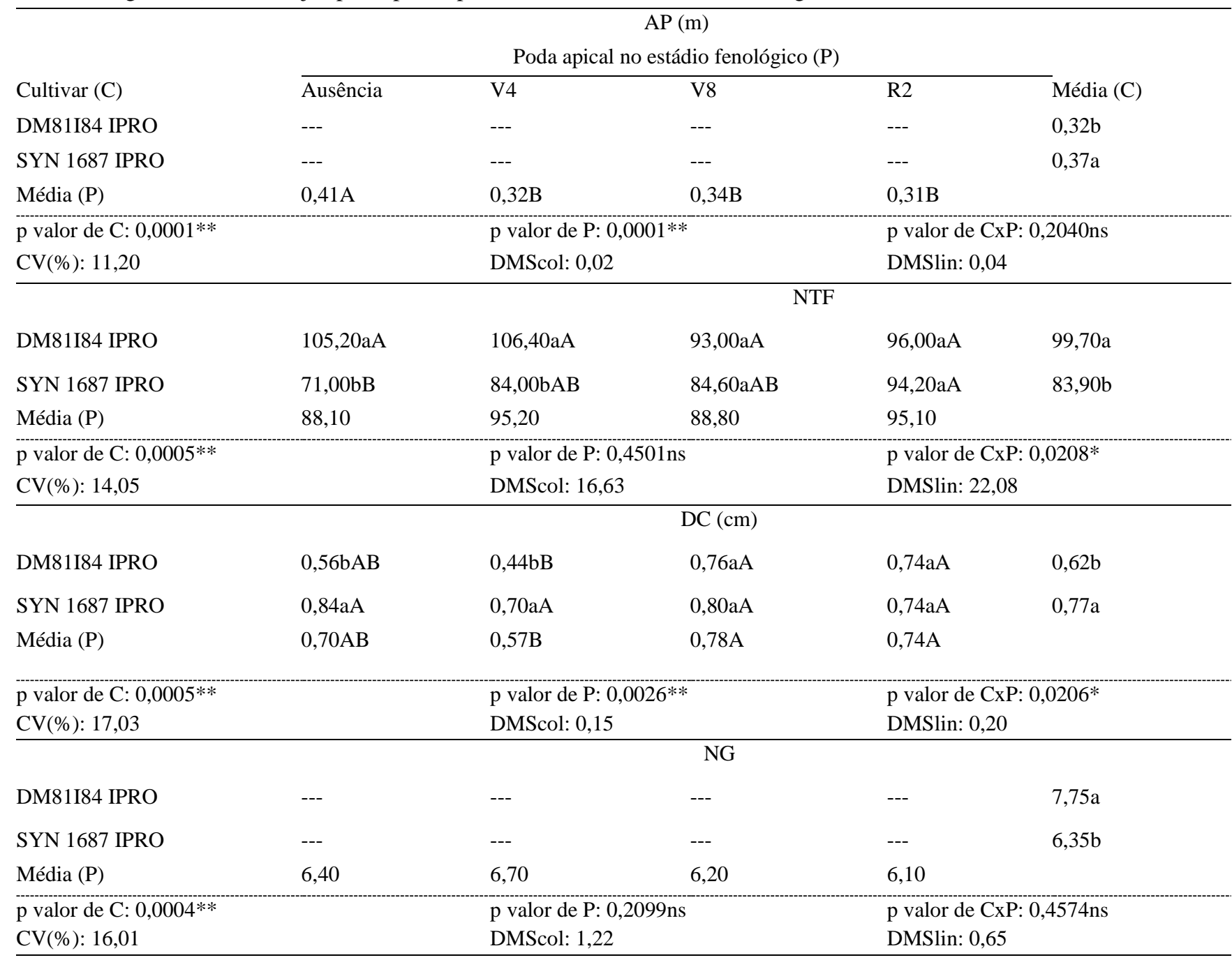

** - significativo ao nível de $1 \%$ de probabilidade $(\mathrm{p}<0,01)$; * significativo ao nível de $5 \%$ de probabilidade $(0,01=<\mathrm{p}<0,05)$; ns - não significativo $(\mathrm{p}>=0,05)$. As médias seguidas pela mesma letra não diferem estatisticamente entre si. Foi aplicado o Teste de Tukey ao nível de $5 \%$ de probabilidade. Fonte: Autores.

Essa diferença entre as cultivares já era esperada, pois mesmo dentro de cada culvitvar ocorre essa variação, sendo isso implica na adaptabilidade dessas cultivar no seu ambiente de produção ou mesmo, quando passam por uma operação agrícola devido à ausência da poda apical, a planta continuou o seu desenvolvimento, o que garantiu uma maior altura, pois isso é resultado da apical do caule (Marques et al, 2019). Segundo Benková et al, 2003 e Yoshihara e Spalding (2017), relatam que o gradiente de auxina auxilia a estrutura da planta regulando a divisão celular e subsequente crescimento e desenvolvimento celular do ápice da planta. A poda faz com que a planta não desenvolva mais a parte apical com isso tendo uma redução no porte da estrutura da planta, mas por consequência ela conseguiu desenvolver ramos laterais.

Para o parâmetro número total de folíolo (NTF) foi observada uma interação significativa entre os fatores, onde a cultivar DM81I84 IPRO foi podada no estádio V4 apresentou a maior média, implicando em aproximadamente em 33,27\% a mais em relação a cultivar SYN 1687 IPRO com ausência de poda. As remoções do meristema apical influenciam no 
crescimento das plantas, na redução o número de nós da haste principal, na altura da planta, na altura de inserção da primeira vagem e também influenciou no número total de folíolo (NTF), principalmente quando realizada aos $20-25 \mathrm{~cm}$ de altura ou estádio V4. A remoção do meristema apical, quando realizada no $6^{\circ}$ trifólio, foi mais eficiente estimulando a ramificação, reduzindo a altura da planta e da primeira vagem. A remoção do meristema apical realizada no $6^{\circ}$ trifólio, na densidade de dez plantas/vaso, permitiu a produção de pelo menos uma vagem por planta viabilizando o uso do método SSD em casa de vegetação (Toledo, 2009).

As plantas apresentaram menor gasto de reservas, um aumento do índice de massa foliar em função da elevada radiação solar, do ambiente adequado ao seu desenvolvimento, promovendo emissão maior número de brotações laterais, com um crescimento vegetativo intenso estabelecendo uma relação entre o aumento de área foliar e a arquitetura de plantas. (Ferreira et al, 2018).

Para o parâmetro diâmetro do caule (DC) a cultivar SYN 1687 IPRO quando não foi realizada a poda apical apresentou maiores valores médios, esse aumento no diâmetro é interessante ocorrer, pois os caules ficam mais robustos e pode desenvolver uma quantidade maior de ramos laterais fazendo que as plantas fiquem mais tolerantes ao acamamento. Já a cultivar DM81I84 IPRO quando podada no estádio V4 não desenvolveu um perfilho ideal com ramos laterais, com isso, em áreas comerciais pode ocorrer um acamamento devido a sua estrutura se torna mais frágil (Anderle et al, 2020). Esse fenômeno ocorre devido à ação da gema apical, que atua no crescimento longitudinal do caule, produz auxina e passa a inibir o surgimento das gemas laterais deixando-as dormentes. Eliminando-se a gema apical, o crescimento passará a ser promovido pelas gemas laterais ativadas pela ausência de auxina. O vegetal apresentará, então, forma copada: pouca altura e mais galhos (Cruz et al, 2016).

No parâmetro número de galhos (NG) foi observado um diferença estatística somente em um fator, onde a cultivar DM81I84 IPRO obteve uma quantidade maior de galhos em torno de 18,06\% a mais em relação à SYN 1687 IPRO e também foi encontrada uma correlação significativa como demonstrado na Figura 1, essa relação mostra que com o aumento do número de galhos também aumenta o número total de folíolo como apresentado na Tabela 3, isso já era esperado, pois quanto mais galho maior a possibilidade ter mais folíolos.

A cultivar em si já é da predominância dela mesma desenvolver galhos laterais por ela ter uma predominância diferente na própria estrutura da planta, esses galhos laterais influencia na quantidade maior massa foliar tornando a planta mais resistente ao acamamento tornando em si uma planta mais seletiva evitando assim o tombamento e quebra de galhos, especialmente quando a planta está em plena produção e atinge elevada massa dos ramos a ter uma produtividade maior no final do seu ciclo (Santos et al, 2020). 
Figura 1: Matriz de correlação de Pearson entre as variáveis número total de folíolos (NTF), diâmetro de caule (DC), número de grãos (NGr) e produtividade em $\mathrm{kg} \mathrm{ha}^{-1}$ da soja quando podada em diferentes estádios fenológicos. Andradina, 2020.

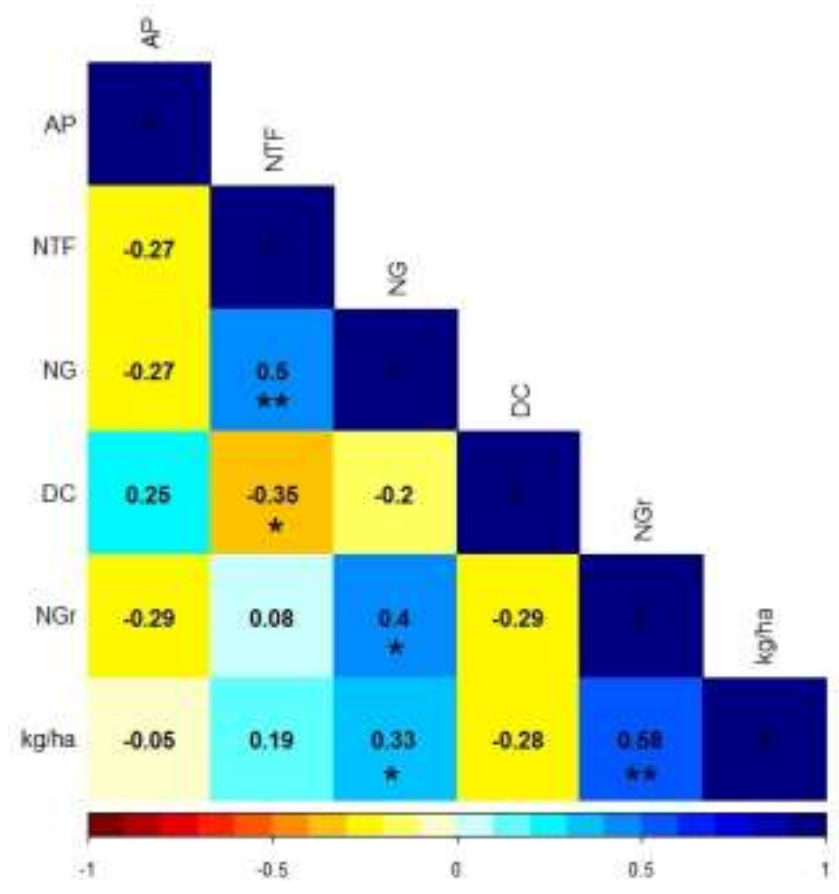

Fonte: Autores.

Tabela 3: Regressões lineares entre as variáveis, número total de folíolos (NTF), diâmetro de caule (DC), número de grãos (NGr) e produtividade em $\mathrm{kg} \mathrm{ha}^{-1}$ da soja quando podada em diferentes estádios fenológicos. Andradina, 2020

\begin{tabular}{llll}
\hline Variável & & p valor da regressão & $\mathrm{R}^{2}$ \\
\hline $\mathrm{NTF}$ & $=49,3991+6,0143 \mathrm{NG}$ & $0,0012^{* *}$ & 0,2493 \\
$\mathrm{DC}$ & $=1,02352106-0,0035 \mathrm{NTF}$ & $0,0299 *$ & 0,1196 \\
$\mathrm{NGr}$ & $=34,4313+4,8111 \mathrm{NG}$ & $0,0102 *$ & 0,1617 \\
$\mathrm{~kg} \mathrm{ha}^{-1}$ & $=1862,2414+93,7077 \mathrm{NG}$ & $0,0432 *$ & 0,1063 \\
$\mathrm{~kg} \mathrm{ha}^{-1}$ & $=1578,3222+13,8194 \mathrm{NGr}$ & $<0,0001 * *$ & 0,3311 \\
\hline
\end{tabular}

Fonte: Autores.

A cultivar SYN 1687 IPRO foi observada uma quantidade inferior de galhos laterais, isso ocorre devido o parâmetro genético da planta por não apresentar essa característica que é a presença de galhos laterais, onde ela apresenta uma estrutura ereta com a quantidade de pouca massa foliar mais sim com um desenvolvimento de altura mais sucessível apresentada no devido trabalho, no entanto por não desenvolver esses galhos laterais a produtividade é bem inferior no seu ciclo final além das dificuldades por ocasião da colheita mecanizada (Tourino et al, 2002).

Segundo Navarro Junior e Costa (2002) a remoção do meristema apical foi mais eficiente em estimular a ramificação na população contendo uma planta por vaso. A remoção do meristema apical, quando realizada aos $25 \mathrm{~cm}$ de altura, aumentou a produtividade e reduziu os trabalhos de tutoramento em condições de cultivo em casa-de-vegetação. Por outro lado, nesse

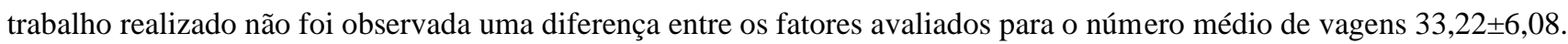

Foi observado somente entre as cultivares de soja uma diferença estatística para o número de grãos (NGr), onde a cultivar DM81I84 IPRO apresentou os melhores resultados com aproximadamente 25,07\% mais em relação a soja SYN 1687 IPRO como demonstrado na Tabela 4, e não foi observada uma diferença no fator na poda apical nos estádios fenológicos da 
soja. Vale destacar que com o aumento no número de galhos apresenta uma correlação com o no número de grãos (Figura 1) que aumenta proporcionalmente o número de galhos como apontado na Tabela 3. O desenvolvimento e enchimento dos grãos não podem ser comprometidos, pois passa a influenciar diretamente na produtividade da cultura, sendo assim a escolha de uma boa cultivar e a população de plantas por área interfere diretamente o rendimento da cultura devido a competição entre as próprias plantas, então plantio com menor densidade populacional a poda das plantas a fim de garantir maior número de galhos e que passa a ocupar espaços vazios de área (Tancredi et al, 2006).

Tabela 4: Valores médios de número de grãos $(\mathrm{NGr})$ e produtividade em $\mathrm{kg} \mathrm{ha}^{-1}$ da soja após a poda apical em diferentes estádios fenológicos. Andradina 2020.

\begin{tabular}{|c|c|c|c|c|c|}
\hline \multirow[b]{3}{*}{ Cultivar (C) } & \multicolumn{4}{|c|}{ NGr } & \multirow[b]{3}{*}{ Média (C) } \\
\hline & \multicolumn{4}{|c|}{ Poda apical no estádio fenológico (P) } & \\
\hline & Ausência & V4 & V8 & $\mathrm{R} 2$ & \\
\hline DM81I84 IPRO & --- & --- & --- & --- & $78,15 \mathrm{a}$ \\
\hline SYN 1687 IPRO & --- & --- & --- & --- & $58,55 \mathrm{~b}$ \\
\hline Média (P) & 68,80 & 74,30 & 65,30 & 65,00 & \\
\hline \multicolumn{2}{|l|}{$\mathrm{p}$ valor de $\mathrm{C}:<0,0001$} & \multicolumn{2}{|c|}{ p valor de P: $0,3156 \mathrm{~ns}$} & \multicolumn{2}{|c|}{ p valor de $\mathrm{CxP}: 0,2101 \mathrm{~ns}$} \\
\hline \multicolumn{2}{|l|}{$\mathrm{CV}(\%): 18,05$} & \multicolumn{2}{|c|}{ DMScol: 7,95 } & \multicolumn{2}{|c|}{ DMSlin:14,95 } \\
\hline \multicolumn{6}{|c|}{$\mathrm{kg} \mathrm{ha}^{-1}$} \\
\hline DM81I84 IPRO & --- & --- & --- & --- & $2708,69 a$ \\
\hline SYN 1687 IPRO & --- & --- & --- & --- & $2337,07 b$ \\
\hline Média (P) & $2637,08 \mathrm{~A}$ & $2680,41 \mathrm{~A}$ & $2640,86 \mathrm{~A}$ & $2133,16 \mathrm{~B}$ & \\
\hline $\mathrm{p}$ valor de C: $<0,0001^{* *}$ & & \multicolumn{2}{|c|}{$\mathrm{p}$ valor de $\mathrm{P}:<0,0001^{* *}$} & \multicolumn{2}{|c|}{$\mathrm{p}$ valor de $\mathrm{CxP}: 0,0954 \mathrm{~ns}$} \\
\hline $\mathrm{CV}(\%): 9,74$ & & \multicolumn{2}{|c|}{ DMScol: 158,43} & \multicolumn{2}{|c|}{ DMSlin: 298,02 } \\
\hline
\end{tabular}

** - significativo ao nível de $1 \%$ de probabilidade $(\mathrm{p}<0,01)$; * - significativo ao nível de $5 \%$ de probabilidade $(0,01=<\mathrm{p}<0,05)$; ns - não significativo $(p>=0,05)$. As médias seguidas pela mesma letra não diferem estatisticamente entre si. Foi aplicado o Teste de Tukey ao nível de $5 \%$ de probabilidade. Fonte: Autores.

Também foi encontrada soja uma diferença estatística de maneira isolada dos fatores para a produtividade em $\mathrm{kg}$ ha 1, onde novamente a cultivar DM81I84 IPRO apresentou os melhores resultados com aproximadamente 13,71\% mais em relação a soja SYN 1687 IPRO como demonstrado na Tabela 4, e também foi observada uma diferença no fator na poda apical nos estádios fenológicos da soja, destacando a poda no estádio V4 com maiores valores implicando em aproximadamente 20,41\% em relação ao estádio R2 que apresentou o menor resultado. Isso demonstra que a poda no estádio R4 não é recomendada, pois com a poda nessa fase de desenvolvimento a planta está direcionando todos os seus fotossimilados para o desenvolvimento e enchimento dos grãos, então com a lesão provocada pela poda à planta pode ter direcionado energia para a recuperação da região lesionada. Novamente vale destacar que com o aumento no número de galhos apresenta uma correlação com o no número de grãos (Figura 1) que aumenta proporcionalmente a produtividade de grãos como apontada na Tabela 3.

Esses valores de produtividade são próximos aos obervados por Cruz et al, 2016 quando estudaram diferentes densidades populacionais de soja, sabendo que a competição inter específica entre as plantas por nutrientes, água do solo e luz, passa a influenciar de maneira negativa a produtividade, então a poda das plantas pode se tornar uma ferramenta para garantir um menor número de plantas por área porém as plantas ficam mais galhos e assim pode ocupar toda a área devido ao brotamento estratégia observada por Toledo et al, 2009. É recomendado mais estudos sobre o assunto, haja vista que os resultados observados em ambiente protegido são mais favoráveis para essa prática, porém não vem sendo destacado em áreas 
comercias, o que implica em mais uma operação mecânica e que o aumento da produtividade pode não compensar a sua prática.

\section{Considerações Finais}

Não é recomendada a poda apical nas cultivares de soja DM81I84 IPRO e SYN 1687 IPRO.

A poda apical na fase reprodutiva da soja influencia de maneira negativa a produtividade da cultura.

A cultivar de soja DM81I84 IPRO se destacou nas características de produção.

O número de galhos apresenta uma correlação positiva com a produtividade na cultura da soja. São necessários novos estudos que abordam o emprego da poda apical na cultura da soja, pois ainda é um assunto muito controvérsio no meio científico.

\section{Referências}

Anderle, G A, Hanauer, T V \& Hermes, E. (2020). Desenvolvimento de plantas de soja sob o uso de adubação mineral e biofertilizante obtido da manipueira. Revista em Agronegócio e Meio Ambiente, 13 (3), 1129-1143. http://dx.doi.org/10.17765/2176-9168.2020v13n3p1129-1143

Banzatto, D A. \& Kronka, S N. (2013). Experimentação Agrícola. 4.ed. Funep, 237p.

Benková, E, Michniewicz, M, Sauer, M, Teichmann, T, Seifertová, D, Jürgens, G, \& Friml, J. (2003). Efflux-dependent auxin gradients as a common module for plant organ formation. Cell, 115 (5): 591-602. http://dx.doi.org/10.1016/s0092-8674(03)00924-3

Borém, A, \& Miranda G V. (2013). Melhoramento de plantas. (6ed). Viçosa: Editora UFV, 523p.

Cline, M G. (1991). Apical dominance. The Botanical Review, 57(4),318-358. http://dx.doi.org/10.1007/bf02858771

Correia, N M, Centurion, M A P C, \& Alves, P L C A. (2005). Influência de extratos aquosos de sorgo sobre a germinação e o desenvolvimento de plântulas de soja. Ciência Rural, 35(3), 498-503. http://dx.doi.org/10.1590/s0103-84782005000300002

Cruz, S C S, Sena Junior, D G, Santos, D M A, Lunezzo, L O, \& Machado, C G. (2016). Cultivo de soja sob diferentes densidades de semeadura e arranjos espaciais. Journal of Neotropical Agriculture, 3(1), 1-6. http://dx.doi.org/10.32404/rean.v3i1.431

Embrapa - Empresa Brasileira de Pesquisa Agropecuária. (2013a). Tecnologias de produção de soja região central do Brasil 2014. Londrina: Embrapa Soja, $265 \mathrm{p}$.

Embrapa - Empresa Brasileira de Pesquisa Agropecuária. (2013b). Sistema brasileiro de classificação de solos. (3.ed.) Brasília, 353p.

Ferreira, A S, Balbinot Junior, A A, Werner, F, Franchini, J C, \& Zucareli, C. (2018). Soybean agronomic performance in response to seeding rate and phosphate and potassium fertilization. Revista Brasileira de Engenharia Agrícola e Ambiental, 22 (3), 151-157.

Fehr, W R, \& Caviness, C E. (1977). Stages of soybean development. Ames: Iowa State University, 12 p.

Marques, J R, Silva, A P, Santos Filho, L, \& Valle, R. (2019). Indução de fluxo foliar precoce em clones de seringueira para uso em sistemas agroflorestais com o cacaueiro. Agrotrópica, 31(1), 17-26. http://dx.doi.org/10.21757/0103- 3816.2019v31n1p17-26

Navarro Júnior, H M, \& Costa, J A. (2002). Contribuição relativa dos componentes do rendimento para produção de grãos em soja. Pesquisa Agropecuária Brasileira, 37(3), 269-274. http://dx.doi.org/10.1590/s0100-204x2002000300006

R Core Team. (2015) R: A language and environment for statistical computing. R Foundation for Statistical Computing, Vienna, Austria. URL: https://www.R-project.org/

Raij, B, Cantarella, H, Quaggio, J Á, \& Furlani, A M C. (1996). Recomendações de adubação e calagem para o Estado de São Paulo. (2.ed.). Campinas: IAC, 285p.

Santos, D M S, Lima, I M O, Silva, K C, \& Steiner, F. (2020). Manejo da adubação nitrogenada para o algodoeiro no sistema de Integração LavouraPecuária. Agricultura 4.0, 6-25. http:// dx.doi.org/10.46420/9786599064159cap1

Sediyama, T, Teixeira, R C, \& Reis, M S. (2005). Melhoramento da soja. In: Borém, A. Melhoramento de espécies cultivadas. Editora UFV. Viçosa, 969p.

Silva, C P, Pistori, M F, Blini, R C B, \& Santana, A P L. (2020). Reguladores vegetais no crescimento e desenvolvimento de plantas cultivadas in vitro. Agricultura 4.0, 46-57. http://dx.doi.org/10.46420/9786599064159cap3

Taiz, L, Zeiger, E, Moller, I, \& Murphy, A. (2017). Fisiologia e desenvolvimento vegetal. 6.ed. Porto Alegre: Artmed, 888p.

Tancredi, F D, Sediyama, T, Reis, M S, Cecon, P R, \& Teixeira, R C. (2006). Efeito da remoção do meristema apical no crescimento e desenvolvimento de plantas de soja em condições de casa de vegetação. Bioscience Journal, 22 (2), 53-60. 
Research, Society and Development, v. 10, n. 5, e46510513688, 2021

(CC BY 4.0) | ISSN 2525-3409 | DOI: http://dx.doi.org/10.33448/rsd-v10i5.13688

Toledo, M R, Tancredi, F D, Sediyama, T, Ribeiro Júnior, J I, \& Reis, M S. (2009). Remoção do meristema apical e adensamento em plantas de soja visando sua utilização no método descendente de uma única semente. Acta Scientiarum. Agronomy, 31(1), 114-119. https://doi.org/10.4025/actasciagron.v31i1.6656

Tourino, M C C, Rezende, P M, \& Salvador, N. (2002). Espaçamento, densidade e uniformidade de semeadura na produtividade e características agronômicas da soja. Pesquisa Agropecuária Brasileira, 37 (8), 1071-1077. http://dx.doi.org/10.1590/s0100-204x2002000800004

Wilkie, J D, Sedgley, M, \& Olesen, T. (2008). Regulation of floral initiation in horticultural trees. Journal of Experimental Botany, 59(12), 3215-3228. http://dx.doi.org/10.1093/jxb/ern188

Yoshihara, T, \& Spalding, E. P. (2017). Lazy genes mediate the effects of gravity on auxin gradients and plant architecture. Plant Physiology, 175 (2), 959-969. http://dx.doi.org/10.1104/pp.17.00942 